\title{
Fingernails - foreign objects in root canal: a case report
}

\author{
C. Pinky ${ }^{1}$, K.S.Ravi ${ }^{2}$, Akash Krishna ${ }^{3}$, Amit Vanka ${ }^{4}$ \\ ${ }^{1}$ M.D.S., Senior Lecturer, Department of Pediatric Dentistry. \\ ${ }^{2}$ M.D.S, Reader, Department of pediatric dentistry. \\ ${ }^{3}$ M.D.S., Senior Lecturer, Department of conservative Dentistry. \\ ${ }^{4}$ M.D.S., Professor \& HOD, Department of Pediatric Dentistry, People's Dental Academy, Bhanpur bypass road, Bhopal.
}

Correspondence:

Department of Pediatric Dentistry,

People's College of Dental Sciences \& Hospital,

Bhanpur bypass road, Bhopal - 462037

E-mail:pinky_0291@yahoo.co.in

Pinky C, Ravi KS, Krishna A, Vanka A. Fingernails - foreign objects in root canal: a case report. J Clin Exp Dent. 2011;3(Supp11):e386-9 http://www.medicinaoral.com/odo/volumenes/v3iSuppl1/jcedv3iSuppl1p386.pdf

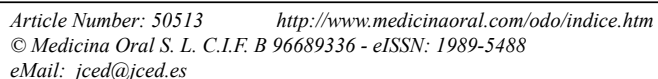

\begin{abstract}
Foreign objects in the pulp chamber or root canal are not unusual findings in patients undergoing root canal treatments in which canals have been left open for drainage. Detailed case history, clinical and radiographic examinations are necessary to come to a conclusion about the nature, size, location of the foreign body and difficulty involved in its retrieval. This kind of situation is more likely to occur in children due to their habit of placing foreign objects in the mouth. The foreign objects may act as a potential source of infection and may later lead to a painful condition. Reported here is an unusual case of metallic pin along with multiple nail pieces retrieved from root canal of a patient with nail biting habit.
\end{abstract}

Key words: traumatic teeth injury, foreign body, fingernails, metallic pin. 


\section{Introduction}

Nail biting is a common oral habit affecting around 30\% of children between $7-10 \mathrm{yrs}$ of age and $45 \%$ of teenagers. The ten fingernails are usually equally bitten and approximately to the same degree (1). In addition children also have a habit of placing foreign objects in the oral cavity. Fortunately, this is usually without consequences. At times, these objects may get lodged inside the pulp chamber or root canal of a tooth and become a potent source of pain and focus of infection in the patient $(2,3)$. Removal of foreign objects from the root canal is a complicated procedure and these must either be removed from the root canal without changing the canal morphology or be bypassed (4). Careful instrumentation, irrigation and floatation are used to remove the obstuction (5).

\section{Case report}

A 11 year old boy reported to the Department of Pedodontics and Preventive Dentistry, People's College of Dental Sciences, Bhopal (India) with a chief complaint of pain in upper left front tooth since past one month. The dental history revealed that patient has had trauma to his permanent left maxillary central incisor about $11 / 2$ yr back. Intraoral examination revealed a complicated enamel dentin fracture with pain on percussion. Intraoral periapical radiograph revealed the presence of a linear radioopaque object in the root canal lodged in the coro-

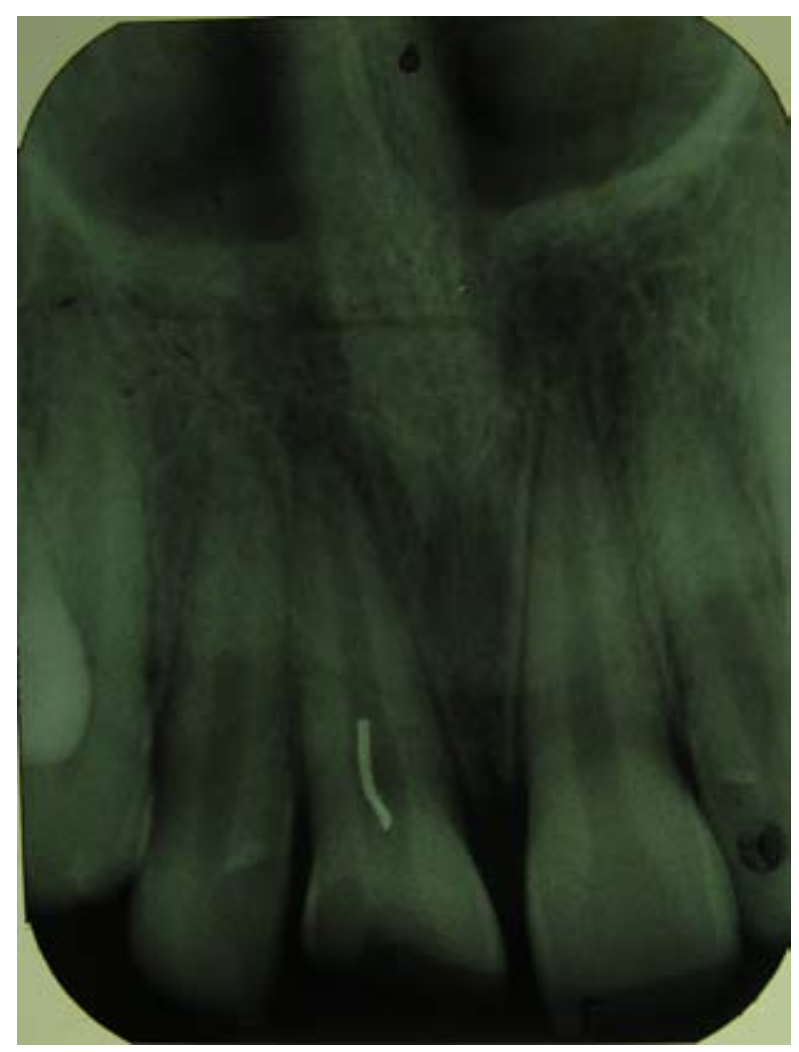

Fig 1. Diagnostic radiograph with foreign body lodged at the coronal third of 21 and widened periodontal ligament space.

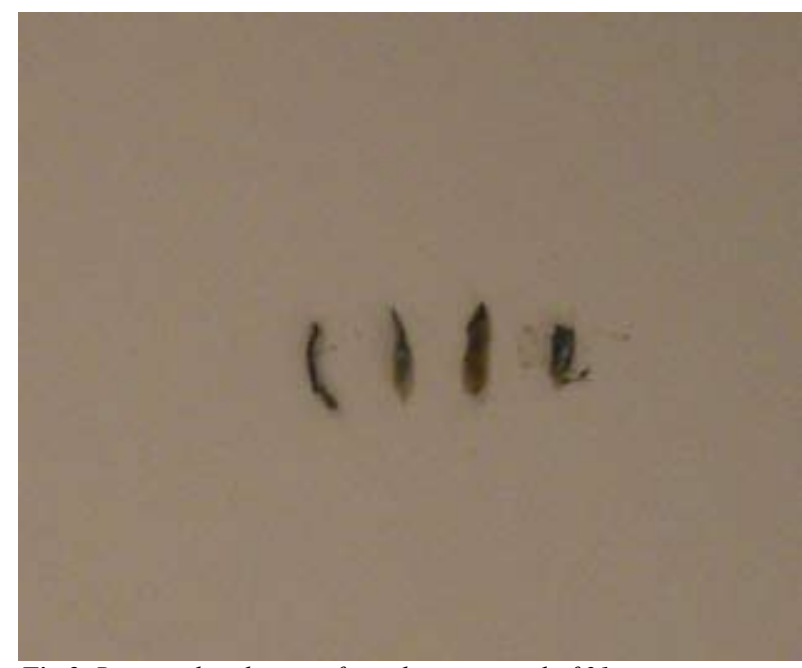

Fig 2. Retrieved nail pieces from the root canal of 21.

nal third of the root. The formulated treatment plan included retrieval of foreign object. The pulp chamber was cleared of debris by copious irrigation and metallic pin removed with K-file. Further debris was presumed to be food matter along with four nail pieces being flushed out of the canal using isotonic saline solution. The retrieved foreign object appeared grayish black in colour measuring about $7 \mathrm{~mm}$. The habit of nail and pencil biting was confirmed from the patient. The tooth was dressed with calcium hydroxide for 2 wks followed by completion of conventional RCT. Following which patient was advised to go for full crown restoration, but parents refused and hence treatment was completed with composite resin build up.

\section{Discussion}

Children often have a tendency to keep foreign objects in the mouth especially when concentrating such as while studying \& or watching T.V. Many times these objects may inadvertently lacerate the oral mucosa, may go into

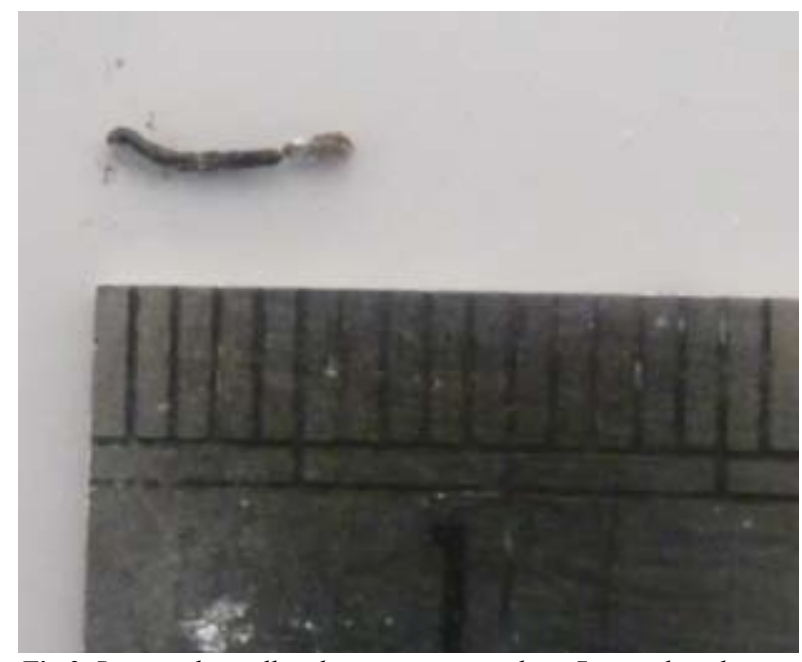

Fig 3. Retrieved metallic object measuring about $7 \mathrm{~mm}$ in length. 
the pharynx or as in this case may even be pushed into the canal of a tooth that is left open (6). Various foreign objects have been reported to be lodged in the root canals and pulp chamber ranging from pencil lead, darning needles, metal screws, to beads, and stapler pins. Grossman, reported retrieval of indelible ink pencil tips, brads, a toothpick, absorbent points and even tomato seed from the root canal of anterior teeth left open for drainage (7).

Toide (8), reported a plastic chopstick embedded in an unerupted supernumerary tooth in the premaxillary region of a 12-yr old Japanese boy. Zillich and Prickens (9) and Turner (10) cited cases wherein hat pins and dressmaker pins that were used to remove the food plugs from root canals of maxillary and mandibular central incisors undergoing endodontic treatment had eventually fractured inside the root canals of their teeth. Harris (11) reported the placement of varied objects within the root canals of maxillary anterior teeth. These included pins, wooden toothpicks, a pencil tips, plastic objects, toothbrush bristles and crayons. However, so far there has been no report of case with nail pieces retrieved from a tooth left open to oral cavity, a special feature of this case report

A conventional practice employed during emergency root canal treatment involves leaving the pulp chamber open where pus continues to discharge through the canal and cannot be dried within a reasonable period of time. Weine recommends that the patient remains in office with a draining tooth for an hour or even more and finally ending the appointment by sealing the access cavity. With the access cavity closed, no new strains of microorganism system are introduced and food debris and foreign body lodgement within the tooth can be avoided (7).

A radiograph can be of diagnostic significance especially if the foreign body is radioopaque. McAuliffe (3) summarized various radiographic methods to be followed to localize a radioopaque foreign object as Parallax views, Vertex occlusal view, Triangulation techniques, Stereo Radiography and Tomography.

Parallax technique involves 2 radiographs taken at different horizontal angles with same vertical direction. Due to parallax the objects appear to travel in the same direction as tube shifts and the object closer to tube appears to move in opposite direction (the so called Same Lingual Opposite Buccal - SLOB) (12). Vertex occlusal view is no longer favored because of relatively high radiation exposure to the lens of the eye and because the primary beam is aimed towards the abdomen. Triangulation is by the use of two views right angle to one another. Interpretation is difficult because of the superimposition of the other incisor teeth over the root. Stereographic views and tomography were not considered due to minimal availability of these facilities in dental operatory.
Specialized radiographic techniques such as radiovisiography, 3D CAT scans can play a role in localization of these foreign objects inside the root canal (3).

However a radiolucent foreign body lodged inside the root canal will not be revealed radiographically. Hence upon encountering resistance in the canal that was left open for a long period of time it is recommended to take proper history about the prevalence of any oral habits and careful instrumentation to prevent apical pushing of the object can help in their successful retrieval.

For retrieval of foreign objects lying in the pulp chamber or canal using ultrasonic instruments, the Massernan kit, modified Castroveijo needle holders have been used (7). Ethylenediaminetetraacetic acid has been suggested as a useful aid in lubricating the canal when attempting to remove the foreign object (3). The Steiglitz forceps have also been described for use of removal of silver points from the root canal. Nehme (13) had recommended the use of operating microscope along with ultrasonic filing to eliminate intracanal obstructions.

Complications can follow if these impacted foci of infection are not eliminated at the right time. Actinimycosis following placement of piece of jewellery chain into a maxillary central incisor has been reported by Goldstein 14. Chronic maxillary sinusitis of dental origin developed due to pushing of foreign bodies into maxillary sinus through the root canals was reported by Costa1 (5).

\section{Conclusion}

The present report has outlined the management of a case of an unusual foreign body in the tooth. Provided one has good patient cooperation, management of the situation can be quite straight forward if the appropriate diagnostic and treatment tools are utilized.

\section{References}

1. Leung AK, Robson WL. Nailbiting. Clin Pediatr 1990;29(12):690-2.

2. A. R. Prabhakar, S. Namineni and H. N. Subhadra. Foreign body in the apical portion of a root canal in a tooth with an immature apex: a case report. Int Endod J 2008;41:920-27.

3. N. McAuliffe, N. A. Drage and B. Hunter. Staple diet: a foreign body in a tooth. Int J Pediatr Dent 2005;15:468-71.

4. Friedman S, Stabholtz A, Tamse A. Endodontic retreatment case selection and techniques : 3 retreatment techniques. J Endod 1990;16:543-49.

5. Stewart GG. Chelation and floatation in endodontic practice: an update. J Am Dent Assoc 1986;113:618-22.

6. Nikhil Srivastava and N Vineeta. Foreign body in the periradicular area. J Endod 2001;27(9):593-4.

7. Aduri R, Reddy RE, Kiran K. Foreign objects in teeth: Retrieval and management. J Indian Soc Pedod Prevent Dent 2009;27(3):17983.

8. Toida M, Ichihara H, Okutomi T, Nakamura K, Ishimaru JI. An unusual foreign body in an unerupted supernumerary tooth. $\mathrm{Br}$ Dent J 1992;173:345-6.

9. Zillich RM, Pickens TN. Patient-induced blockage of the root canal: report of a case. Oral Surg Oral Med Oral Pathol 1982;54:68990.

10. Turner $\mathrm{CH}$. An unusual foreign body. Oral Surg Oral Med Oral 
Pathol 1983;56:223.

11. Harris WE. Foreign bodies in root canals: report of two cases. J Am Dent Assosc 1972;85:906-11.

12. Mason C, Papadakou P and Roberts GJ. The radiographic localization of impacted maxillary canines: a comparison of methods. Eur J Ortho 2001;23:25-31.

13. Nehme WB. Elimination of intracanal metallic obstruction by abrasion using an operational microscope and ultrasonics. J Endod 2001;27:365-7.

14. Goldstein BH, Scuibba JJ, Laskin DM. actinomycosis of the maxi1la: a case report. J Oral Surg 1972;30:362-6.

15. Costa F, Robiomy M, Toro C, Sembronio S, Politi M. endoscopically assisted procedure for the removal of a foreign body from the maxillary sinus and contemporary endodontic surgical treatment of the tooth. Head Face Med 2006;8:37. 